\title{
Improving Knowledge that Alcohol Can Cause Cancer is Associated with Consumer Support for Alcohol Policies: Findings from a Real-World Alcohol Labelling Study
}

\author{
Ashini Weerasinghe ${ }^{1}\left(\mathbb{D}\right.$, Nour Schoueri-Mychasiw ${ }^{1}$, Kate Vallance ${ }^{2}{ }^{\circledR}$, Tim Stockwell ${ }^{2}$, \\ David Hammond ${ }^{3}$, Jonathan McGavock ${ }^{4}{ }^{\mathbb{D}}$, Thomas K. Greenfield ${ }^{5}$, Catherine Paradis ${ }^{6}$ \\ and Erin Hobin ${ }^{1, *}$ \\ 1 Public Health Ontario, Toronto, ON M5G 1V2, Canada; Ashini.Weerasinghe@oahpp.ca (A.W.); \\ Nour.Schoueri-Mychasiw@oahpp.ca (N.S.-M.) \\ 2 Canadian Institute for Substance Use Research, University of Victoria, Victoria, BC V8P 2Y2, Canada; \\ vallance@uvic.ca (K.V.); timstock@uvic.ca (T.S.) \\ 3 School of Public Health and Health Systems, University of Waterloo, Waterloo, ON N2L 3G1, Canada; \\ david.hammond@uwaterloo.ca \\ 4 Children's Hospital Research Institute of Manitoba, University of Manitoba, Winnipeg, MB R3E 3P4, Canada; \\ JMcGavock@chrim.ca \\ 5 Alcohol Research Group, Public Health Institute, Emeryville, CA 94608, USA; tgreenfield@arg.org \\ 6 Canadian Centre for Substance Use and Addiction, Ottawa, ON K1P 5E7, Canada; CParadis@ccsa.ca \\ * Correspondence: erin.hobin@oahpp.ca; Tel.: 1-647-260-7198
}

Received: 29 October 2019; Accepted: 21 November 2019; Published: 7 January 2020

\begin{abstract}
Knowledge that alcohol can cause cancer is low in Canada. Alcohol labels are one strategy for communicating alcohol-related harms, including cancer. Extending existing research observing an association between knowledge of the alcohol-cancer link and support for alcohol policies, this study examined whether increases in individual-level knowledge that alcohol is a carcinogen following an alcohol labelling intervention are associated with support for alcohol polices. Cancer warning labels were applied to alcohol containers at the intervention site, and the comparison site did not apply cancer labels. Pre-post surveys were conducted among liquor store patrons at both sites before and two-and six-months after the intervention was stopped due to alcohol industry interference. Limiting the data to participants that completed surveys both before and two-months after the cancer label stopped, logistic regression was used to examine the association between increases in knowledge and support for policies. Support for pricing and availability policies was low overall; however, increases in individual-level knowledge of the alcohol-cancer link was associated with higher levels of support for pricing policies, specifically, setting a minimum unit price per standard drink of alcohol (OR $=1.86,95 \% \mathrm{CI}$ : 1.11-3.12). Improving knowledge that alcohol can cause cancer using labels may increase support for alcohol policies. International Registered Report Identifier (IRRID): RR2-10.2196/16320
\end{abstract}

Keywords: cancer prevention; alcohol; alcohol policy; alcohol warning labels

\section{Introduction}

Alcohol consumption is a leading risk factor for burden of disease, contributing to an estimated 3 million deaths ( $5 \%$ of all deaths) and 133 million disability-adjusted life years (DALYs) ( $5 \%$ of all DALYs) globally in 2016 [1]. The ethanol in alcoholic beverages has been classified as a Group 1 carcinogen (the highest category of risk) since 1988, and recent evidence indicated that alcohol consumption can cause 
at least seven types of cancers [2-4]. In 2016, alcohol use accounted for approximately $4 \%$ of cancer deaths and cancers were the predominant source of total alcohol-attributable deaths in higher-income countries, particularly among those over age 50 [5]. The relationship between alcohol consumption and increased risk of certain cancers has now been extended beyond heavy alcohol consumption to include low and moderate levels of consumption, and to all types of alcohol including wine, beer, and spirits $[5,6]$.

Despite the serious health harms caused by alcohol, 2 billion people currently consume alcohol regularly, and global consumption is expected to increase $17 \%$ by 2030 [7]. In Canada, alcohol is the most widely used psychoactive substance (excluding caffeine), with 78\% of Canadian adults aged 15+ (approximately 22 million) consuming alcohol in the past year and an annual per capita consumption of 8.2 litres, more than double the global average [8-10]. The number of hospitalizations fully attributable to alcohol across Canada is higher than hospitalizations from heart attacks and the annual cost of alcohol (\$14.6B) exceeds the costs from cannabis and all illicit substances combined and is similar to tobacco [11,12]. Consistent with international data, the public perception of alcohol in Canada is that it is less harmful than tobacco and other substances, and it is not understood to be a carcinogen, or is only considered dangerous at high levels of consumption [13-17]. A recent Canadian survey also found that $69 \%$ of participants indicated that they would reduce their alcohol consumption if they learned that alcohol increases cancer risk [13]. Alcohol policy in Canada has been largely neglected relative to emerging initiatives addressing tobacco control, responses to the opioid overdose crisis and vaping, and restrictions imposed on the new legal cannabis market [12]. Coordinated, comprehensive, and effective policies are needed to increase awareness of the risks of alcohol and reverse trends of high alcohol-related harms and costs.

Studies have indicated that alcohol control policies have a protective effect against alcohol use and related harm $[18,19]$. Indeed, stricter alcohol policy environments can gradually shift a population towards lighter alcohol use [18] and are also associated with lower secondhand effects of alcohol [20]. While a large robust evidence base consistently suggests that restricting the availability and marketing and regulating the price of alcohol are the most cost-effective and easy-to-implement measures for reducing population-level alcohol consumption and harms [21-30], these policies often endure strong opposition from sections of the public and hence also some policy-makers [31-33]. Since alcohol is perceived by many as a relatively benign substance, trying to limit or contain alcohol consumption, even when supported by good evidence, is often resisted by some in the public who see availability, price and convenience of purchase as a societal good [34]. Public approval of alcohol policies is critical for social change. Information-based interventions, such as media campaigns, may be promising approaches for increasing knowledge of the negative consequences of alcohol and changing public opinion on alcohol policies shown to reduce per capita consumption and harms [35-38]. It is likely that the widespread awareness of health risks associated with smoking contributed to the public support for restrictive tobacco control policies [39]. Therefore, greater investment in educating the public about the risks associated with alcohol may be needed to create a more supportive environment for enacting effective alcohol control policies.

Alcohol container labels are one potentially effective information-based strategy for increasing consumer knowledge about the negative consequences of alcohol and are recommended by the World Health Organization [40,41]. Labels influence behaviour by attracting consumers' attention and keeping the message in consumers' minds through repeated exposure at key points of contact-the point-of-purchase and the point-of-pour [42]. Labels are appealing because of their low cost to regulators and unparalleled reach among drinkers, with the heaviest drinkers exposed most often [43]. Several lab and online studies testing alcohol warning messages have suggested that cancer warning labels are effective for increasing knowledge of alcohol as a risk factor for cancer and enhancing motivations to reduce alcohol use compared to other health messages [17,44-47].

A real-world alcohol labelling intervention study was implemented in Yukon, Canada with the purpose of testing the impact of the labels on consumer awareness of alcohol-related health harms, such as cancer and drinking behaviours. As shown in Figure 1, the alcohol labelling intervention consisted of three rotating labels: (1) a cancer warning including specific references to breast and colon 
cancers-two prevalent, often fatal cancers in Canada [48], (2) Canada's low-risk drinking guidelines, and (3) standard drink information (four separate labels were developed for wine, spirits, coolers, and beer). Consistent with previous studies examining effective product label design, the intervention labels were relatively large in size to make them easily noticed and read, were full colour with a bright yellow background and red border so that they stand out on the container, and had messages providing new information and were rotated to avoid wear out [41,47,49-55]. A recent evaluation of the label intervention conducted by Hobin et al., on which the analyses of this paper are also based, found that participant knowledge of the link between alcohol and cancer was approximately $25 \%$ before the alcohol labelling intervention [56]. These findings are consistent with the low levels of awareness of the alcohol-cancer link in national estimates in Canada in 2008, and are also similar to findings from surveys in Australia and the UK [14,57,58]. Extending existing cross-sectional research from Europe and Australia observing an association between awareness of alcohol as a carcinogen and support for alcohol control policies [35-38], the main objective of this paper was to examine whether increases in individual-level knowledge of the link between alcohol and cancer following an alcohol labelling intervention are associated with stronger support for alcohol policy measures.

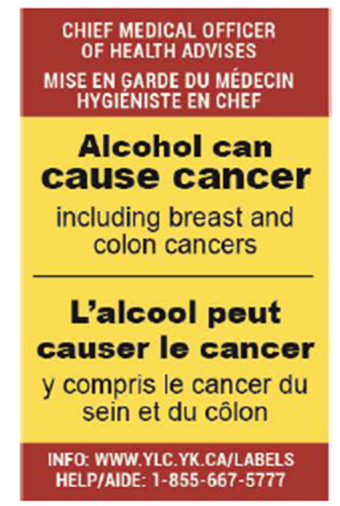

(a)

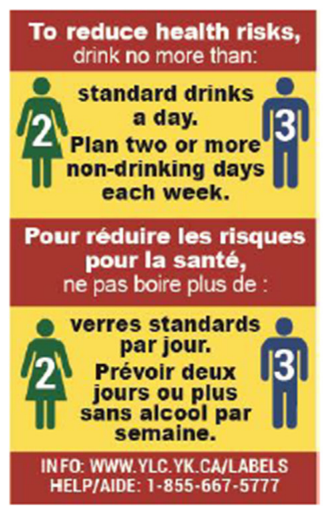

(b)

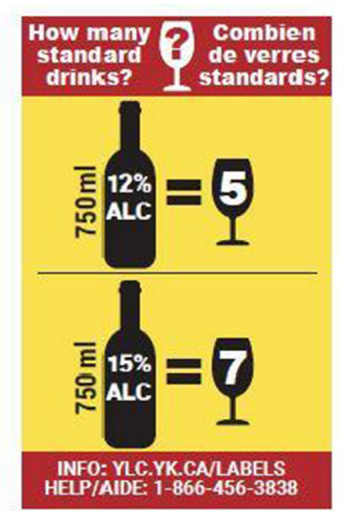

(c)

Figure 1. Intervention alcohol warning labels (actual size $5.0 \mathrm{~cm} \times 3.2 \mathrm{~cm}$ ): (a) Label 1: Cancer Warning; (b) Label 2: Canada's Low-Risk Drinking Guidelines; (c) Label 3: Standard Drink Information (example for wine). Note: Alcohol containers sold in the liquor store in the intervention site were labelled with one of the three labels displayed in Figure 1.

\section{Materials and Methods}

\subsection{Study Design}

The study design has been described elsewhere [59]. Briefly, two waves of longitudinal surveys were scheduled among cohort participants in the intervention and comparison sites four months before (wave 1: May-June 2017) and eight-months after (wave 2: May-June 2018) the intervention labels were implemented. The two intervention labels with a cancer warning and national drinking guidelines were applied to all alcohol containers in the intervention site, with the exception of select local and single serve beer and cider ( 3\% of products), starting 20 November 2017 . The standard drink labels were to be introduced shortly thereafter. However, one month into the eight-month study period, the government in the intervention site halted its participation in the study due to significant pressure from Canada's alcohol producers and stopped applying labels $[59,60]$. Based on the remaining label stock, approximately 47,000 cancer warning labels and 53,000 national drinking guidelines labels were applied to alcohol containers within the one-month period. In April 2018, the government in the intervention site resumed their participation in the study under the condition that the cancer warning label be excluded from rotation. Thus, the drinking guidelines label and the standard drink label were reinstated from April to July 2018. The study design was modified due to the interruption in the intervention, and wave 2 surveys were conducted in February 2018 in order to capture the impact of the 
shortened intervention. Wave 3 surveys were conducted from June 2018 to the end of the study period in July 2018. In waves 2 and 3, participants who provided their contact information in a preceding wave were emailed survey instructions, a unique survey link, and an e-transfer as remuneration. Additionally, due to attrition, the sample was replenished using wave 1 recruitment procedures in liquor stores in both sites. All the survey periods lasted six weeks, the surveys took approximately 18 minutes to complete, and survey protocols and measures were consistent across waves and sites. The survey was completed in English only as the majority of the residents in the intervention and comparison sites speak English at home and work [61,62]. The study was approved by the Research Ethics Boards at Public Health Ontario (ID 2017-010.04) and the University of Victoria (Protocol 17-161).

\subsection{Participants}

Participants were recruited by trained research assistants as they exited liquor stores in both the intervention and comparison sites using a standard intercept technique of approaching every person that passed a pre-identified landmark in the liquor store. At the time of initial recruitment, participants were adults of legal drinking age (19+), current drinkers ( $\geq 1$ drink in past 30 days), residing in the intervention and comparison sites, bought alcohol at the liquor store, and did not report being pregnant or breastfeeding.

\subsection{Measures}

\subsubsection{Knowledge of Alcohol as a Carcinogen}

Knowledge of alcohol as a carcinogen was measured by asking participants, "Based on what you know or believe, can drinking alcohol cause ... ?" for each of breast cancer, liver disease, the flu, and [when pregnant cause] harm to unborn babies. Only responses to the cancer item are reported here. Responses for "breast cancer" were dichotomised as 'Caused by alcohol' (Yes) versus 'Not caused by alcohol' (No/Don't know). Given that in the alcohol label intervention, the label with the cancer warning was implemented on alcohol containers in the liquor store in the intervention site between waves 1 and 2 only, "increases" in knowledge of alcohol as a carcinogen following the alcohol labelling intervention is defined in this paper as a participant who responded 'Not caused by alcohol' in wave 1 and responded 'Caused by alcohol' in wave 2 for breast cancer.

\subsubsection{Support for Alcohol Policies}

Support for alcohol policies was measured using seven items previously used in research conducted in Australia and the UK [35-37]. These items were first introduced in the wave 2 survey, with no wave 1 data available. To assess support for alcohol policies, participants were asked, "To reduce the problems associated with excessive alcohol use, to what extent would you support or oppose each of the following policies ... ?", followed by a list of seven policy options targeting alcohol price, availability, and marketing (Figure 2). These policy options were adapted from the study by Buykx et al., [37] as well as a public opinion survey conducted by the Yukon government to inform the local liquor act in 2017 [63]. Responses were recorded on a five-point Likert scale $(1=$ Strongly oppose and 5 = Strongly support), and included 'Don't know', 'Prefer not say' and 'Missing' as options.

\subsubsection{Socio-Demographics}

Socio-demographic measures included age, sex, ethnicity (White, Aboriginal, and Other/Don't know/Prefer not to say/Missing), education [low (completed high school or less), medium (completed trades or college certificate, some university or university certificate below Bachelor's), high (university degree or post-graduation), and unknown (Don't know/Prefer not to say/Missing)], and income [low $(<\$ 30,000)$, medium $(\$ 30,000-\$ 59,999)$, high $(\geq \$ 60,000)$, and unknown (Don't know/Prefer not to say/Missing)]. 


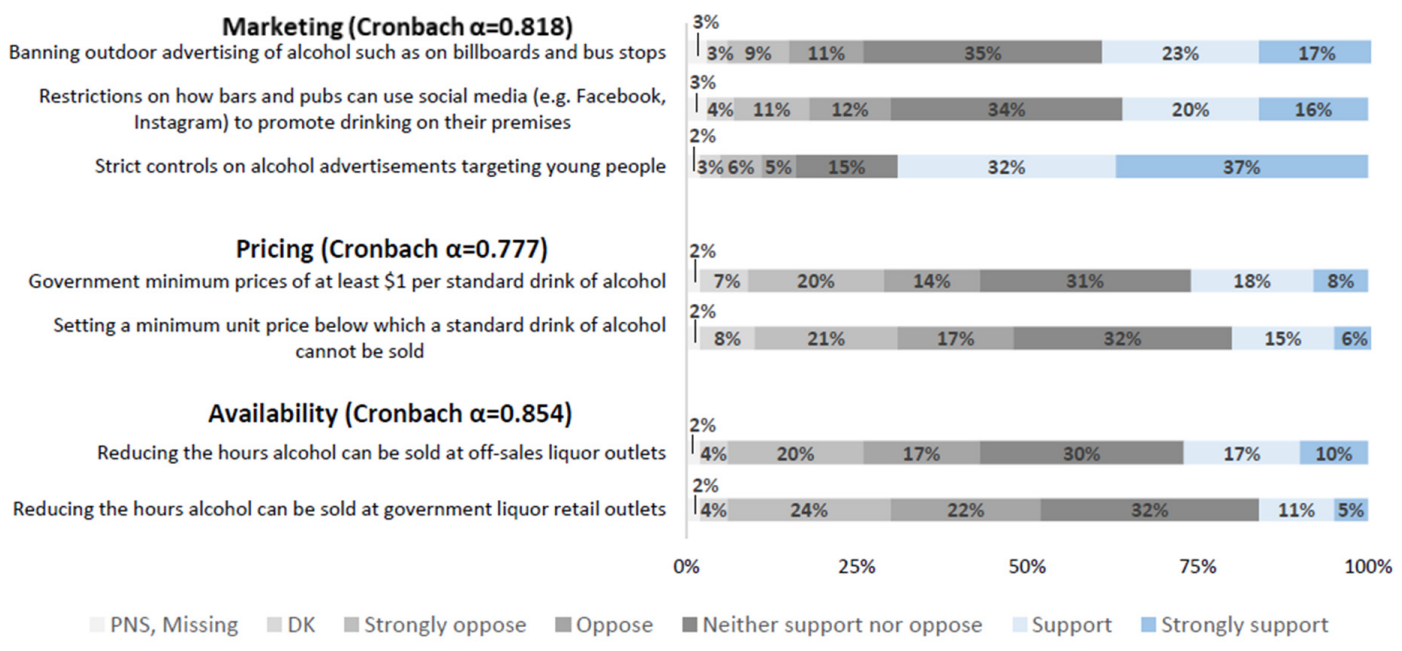

Figure 2. Level of support for alcohol policies from participants' last survey wave completed. Percent missing varies from $1.16 \%$ to $1.56 \%$ for seven policy measures. Note: DK = Don't know, PNS = Prefer not to say.

\subsubsection{Other Covariates}

Health literacy was assessed using the Newest Vital Sign assessment tool [64] and responses were categorized as limited ( $\leq 1$ correct responses), possibility of limited (2-3 correct responses), adequate literacy (4-6 correct responses), and unknown (Don't know/Prefer not to say/Missing). Alcohol use was measured using the quantity/frequency method [65]. Participants were asked to indicate how often they drank alcoholic beverages in the past six months and how many drinks they usually drank per occasion. Responses were combined to provide a mean number of drinks per week and categorized using Canada's low-risk drinking guidelines: low risk ( $\leq 10$ for females/15 for males per week), risky (11-19/16-29 per week), high risk ( $\geq 20 / 30$ per week) [66], and unknown (Don't know/Prefer not to say/Missing).

\subsection{Statistical Analysis}

The analyses involved four stages. Firstly, to investigate trends in participant responses between policy measures within each of the three policy domains and determine if the policy measures could be combined, the reliability of internal consistency was measured using the Cronbach alpha coefficient $(\alpha)$. Values for $\alpha$ range from $0-1$, with higher values indicating better reliability. Good reliability was established for all three alcohol policy domains (Cronbach $\alpha=0.854$ for availability, 0.777 for pricing, and 0.818 for marketing) and thus, the measures in each domain were combined into a single outcome for price, availability, and marketing. Secondly, responses for support within each policy domain was dichotomised into "Support" (either Strongly support or Support any of the policy measures within each domain) or "Do Not Support" (either Strongly oppose, Oppose, neither support nor oppose, or Don't know to all of the policy measures within each domain). Thirdly, to estimate predictors of policy support, three separate logistic regression models were conducted with the three policy domains, price, availability, and marketing, as outcomes. Socio-demographics, alcohol use and knowledge that alcohol can cause cancer were entered as independent variables. Ethnicity was defined as White vs. Other (Aboriginal/Other/Don't know/Prefer not to say/Missing). Education, income, and health literacy were found to be correlated; thus, to improve the stability of the models, only education was used. Policy support measures were first introduced in the wave 2 survey; thus, data from survey waves 2 and 3 only were used in these analyses, using responses from participants' last wave completed. Lastly, to examine whether increases in knowledge of the alcohol-cancer link following the alcohol labelling intervention are associated with support for alcohol policies, three logistic regression analyses were conducted using data limited to participants that completed surveys both in waves 1 and 2, adjusting for socio-demographics and alcohol use. A sensitivity analysis evaluated the effect of adjusting for heavy episodic drinking to improve estimation of alcohol consumption, as previous 
research suggested that the quantity/frequency method alone is a relatively weak measure of alcohol use [67]. This analysis did not substantially alter the main results in terms of direction, magnitude and statistical significance; thus, to increase the study power and efficiency, the results presented were not adjusted for heavy episodic drinking. As per agreement with the local territorial government partners, ethnicity is included in the sample description and adjusted for in the analyses, but not reported in the results. All analyses were performed using SAS 9.3 (SAS Institute Inc., Cary, NC, USA, 2013).

\section{Results}

In total, 1730 unique participants were included in this study (Table 1). The overall response rate was $8.6 \%$ [68], with $53.2 \%$ of participants retained at wave 2 and $47.5 \%$ retained at wave 3 . At the time of initial recruitment, $32.0 \%$ of participants were aware of the alcohol link: $23.0 \%$ from wave 1 , $53.4 \%$ from wave 2 , and $23.7 \%$ from wave 3 . Participants lost to follow-up across the three survey waves were more likely to be younger, male, have lower education, income and literacy, consume high or unknown levels of alcohol, and be in the comparison site.

Table 1. Sample characteristics by Knowledge of Alcohol-Cancer Link at time of initial recruitment (n = 1730).

\begin{tabular}{|c|c|c|}
\hline \multicolumn{3}{|c|}{ Knowledge of Alcohol as a Carcinogen } \\
\hline \multirow[t]{2}{*}{ Characteristic } & $\begin{array}{l}\text { Not Caused by Alcohol } \\
(\mathbf{N}=1177)\end{array}$ & $\begin{array}{l}\text { Caused by Alcohol } \\
\quad(N=553)\end{array}$ \\
\hline & $\mathbf{N}(\%)$ & $\mathbf{N}(\%)$ \\
\hline \multicolumn{3}{|l|}{ Wave of initial recruitment $* * *$} \\
\hline 1 & $390(33.14)$ & $127(22.97)$ \\
\hline 2 & $516(43.84)$ & $295(53.35)$ \\
\hline 3 & $271(23.02)$ & $131(23.69)$ \\
\hline \multicolumn{3}{|l|}{ Site * } \\
\hline Intervention & $697(59.22)$ & $359(64.92)$ \\
\hline Comparison & $480(40.78)$ & $194(35.08)$ \\
\hline Age [Mean (SD)] & $44.82(14.32)$ & $44.65(14.53)$ \\
\hline \multicolumn{3}{|l|}{ Age Categories } \\
\hline $19-24$ & $92(7.82)$ & $45(8.14)$ \\
\hline $25-44$ & $480(40.78)$ & $228(41.23)$ \\
\hline $45+$ & $605(51.40)$ & $280(50.63)$ \\
\hline \multicolumn{3}{|l|}{ Ethnicity } \\
\hline White & $799(67.88)$ & $386(69.80)$ \\
\hline Aboriginal & $225(19.12)$ & $104(18.81)$ \\
\hline Other & $153(13.00)$ & $63(11.39)$ \\
\hline \multicolumn{3}{|l|}{ Sex $* *$} \\
\hline Male & $622(52.85)$ & $255(46.11)$ \\
\hline Female & $555(47.15)$ & $298(53.89)$ \\
\hline \multicolumn{3}{|l|}{ Education Levels *** } \\
\hline Low (Completed high school or less) & $241(20.48)$ & $88(15.91)$ \\
\hline Medium (Trades or college certificate, some & & \\
\hline $\begin{array}{l}\text { university or university certificate } \\
\text { below Bachelor) }\end{array}$ & $420(35.68)$ & $171(30.92)$ \\
\hline High (Bachelor degree or higher) & $445(37.81)$ & $266(48.10)$ \\
\hline Unknown (DK, PNS, Missing) & $71(6.03)$ & $28(5.06)$ \\
\hline
\end{tabular}


Table 1. Cont.

\begin{tabular}{|c|c|c|}
\hline \multicolumn{3}{|c|}{ Knowledge of Alcohol as a Carcinogen } \\
\hline \multirow[t]{2}{*}{ Characteristic } & $\begin{array}{l}\text { Not Caused by Alcohol } \\
\qquad(\mathrm{N}=1177)\end{array}$ & $\begin{array}{l}\text { Caused by Alcohol } \\
\qquad(\mathrm{N}=553)\end{array}$ \\
\hline & $\mathbf{N}(\%)$ & $\mathbf{N}(\%)$ \\
\hline \multicolumn{3}{|l|}{ Income Levels } \\
\hline Low $(<\$ 30,000)$ & $138(11.72)$ & $76(13.74)$ \\
\hline Medium $(\$ 30,000$ to $<\$ 60,000)$ & $188(15.97)$ & $85(15.37)$ \\
\hline High $(\geq \$ 60,000)$ & $713(60.58)$ & $341(61.66)$ \\
\hline Unknown (DK, PNS, Missing) & $138(11.72)$ & $51(9.22)$ \\
\hline \multicolumn{3}{|l|}{ Alcohol Use * } \\
\hline $\begin{array}{l}\text { Low risk volume } \leq 10 \text { for females/15 for } \\
\text { males per week }\end{array}$ & $866(73.58)$ & $402(72.69)$ \\
\hline Risky volume 11-19/16-29 per week & $74(6.29)$ & $44(7.96)$ \\
\hline High risk volume $\geq 20 / 30$ per week & $114(9.69)$ & $70(12.66)$ \\
\hline Unknown (DK, PNS, Missing) & $123(10.45)$ & $37(6.69)$ \\
\hline \multicolumn{3}{|l|}{ Health Literacy Levels ** } \\
\hline Limited literacy (score $\leq 1)$ & $364(30.93)$ & $129(23.33)$ \\
\hline Possibility of limited literacy (score 2-3) & $210(17.84)$ & $123(22.24)$ \\
\hline Adequate literacy (score 4-6) & $527(44.7)$ & $266(48.10)$ \\
\hline Unknown (DK, PNS, Missing) & $76(6.46)$ & $35(6.33)$ \\
\hline
\end{tabular}

${ }^{*}$ Pearson $X^{2}$ test, $p<0.05,{ }^{* *}$ Pearson $X^{2}$ test, $p<0.01,{ }^{* * *}$ Pearson $X^{2}$ test, $p<0.001$, DK $=$ Don't know, PNS $=$ Prefer not to say.

\subsection{Associations Between Knowledge of Alcohol as a Carcinogen and Support for Alcohol Policies}

In the participants' last survey in either of waves 2 or 3, 37.0-37.2\% were aware that alcohol can cause cancer, and the level of support for each of the seven alcohol pricing, availability, and marketing policies are presented in Figure 2. Knowledge of alcohol as a carcinogen was significantly associated with support for policies controlling alcohol pricing ( $\mathrm{OR}=1.87,95 \% \mathrm{CI}: 1.51-2.32)$, availability $(\mathrm{OR}=1.62$, 95\% CI: 1.30-2.01), and marketing (OR = 1.44, 95\% CI: 1.12-1.86) (Table 2).

Support for alcohol pricing policies was associated with having a high level of education (OR $=1.59$, 95\% CI: 1.15-2.20) and not supporting alcohol pricing polices was associated with risky levels of alcohol use (OR $=0.55,95 \%$ CI: 0.35-0.86), relative to the referent. Support for alcohol availability policies was associated with being in the intervention site ( $\mathrm{OR}=1.36,95 \% \mathrm{CI}: 1.08-1.72)$, female (OR $=1.31,95 \% \mathrm{CI}$ : 1.06-1.63), and aged $45+(\mathrm{OR}=2.06,95 \% \mathrm{CI}: 1.27-3.33)$, relative to the referent. Similarly, support for alcohol marketing policies was associated with being female (OR $=1.51,95 \%$ CI:1.20-1.92), aged 25-44 $(\mathrm{OR}=1.80,95 \% \mathrm{CI}: 1.19-2.71)$ and $45+(\mathrm{OR}=2.41,95 \% \mathrm{CI}: 1.60-3.63)$, and having a high level of education $(\mathrm{OR}=1.84,95 \% \mathrm{CI}: 1.30-2.59)$, relative to the referent. Not supporting alcohol marketing policies was associated with unknown ( $\mathrm{OR}=0.55,95 \% \mathrm{CI}$ : 0.37-0.82) levels of alcohol use, relative to the referent.

\subsection{Associations between Increases in Knowledge of Alcohol as A Carcinogen and Alcohol Policies}

Among the participants that completed surveys in both waves 1 and 2, an increase in knowledge of alcohol as a carcinogen was observed among $20.2-20.3 \%$ of participants. An increase in knowledge that alcohol is a carcinogen, relative to those without an increase, was positively associated with support for policies controlling alcohol pricing (39.1\% vs. $26.5 \%$; OR $=1.86,95 \%$ CI: $1.11-3.12$ ). While a higher proportion of those with an increase in knowledge that alcohol can cause cancer, relative to those without an increase in knowledge, supported policies controlling alcohol availability $(27.3 \%$ vs. $25.2 \%$; OR $=1.15,95 \%$ CI: $0.66-1.99)$ and marketing (81.6\% vs. $75.8 \%$; OR $=1.40,95 \%$ CI: $0.73-2.71)$, these differences did not reach conventional levels of statistical significance (Table 3). 
Table 2. Adjusted odds ratios (OR) and 95\% confidence intervals (CI) of support for policy by demographics, alcohol use and knowledge of alcohol as a carcinogen.

\begin{tabular}{|c|c|c|c|c|c|c|c|c|c|}
\hline \multirow[t]{2}{*}{ Variable } & \multicolumn{4}{|c|}{$\begin{array}{l}\text { Availability } \\
(N=1680)\end{array}$} & \multicolumn{3}{|c|}{$\begin{array}{c}\text { Pricing } \\
(\mathrm{N}=1681)\end{array}$} & \multicolumn{2}{|r|}{$\begin{array}{l}\text { Marketing } \\
(\mathrm{N}=1677)\end{array}$} \\
\hline & $\mathbf{N}$ & N (\%) & $\begin{array}{l}\text { Adjusted OR } \\
(95 \% \mathrm{CI})^{1}\end{array}$ & $\mathbf{N}$ & $\mathbf{N}(\%)$ & $\begin{array}{l}\text { Adjusted OR } \\
(95 \% \mathrm{CI})^{1}\end{array}$ & $\mathbf{N}$ & N (\%) & $\begin{array}{c}\text { Adjusted OR (95\% } \\
\text { CI) }{ }^{1}\end{array}$ \\
\hline \multicolumn{10}{|l|}{$\begin{array}{l}\text { Knowledge of alcohol as a } \\
\text { carcinogen }\end{array}$} \\
\hline Not caused by alcohol & 1055 & $278(26.35)$ & 1.00 (ref) & 1056 & $277(26.23)$ & 1.00 (ref) & 1056 & $767(72.63)$ & 1.00 (ref) \\
\hline Caused by alcohol & 625 & $232(37.12)$ & $1.62(1.30,2.01)$ & 625 & $254(40.64)$ & $1.87(1.51,2.32)$ & 621 & 499 (80.35) & $1.44(1.12,1.99)$ \\
\hline \multicolumn{10}{|l|}{ Sex } \\
\hline Male & 847 & $229(27.04)$ & 1.00 (ref) & 847 & $254(29.99)$ & 1.00 (ref) & 841 & $602(71.58)$ & 1.00 (ref) \\
\hline Female & 833 & $281(33.73)$ & $1.31(1.06,1.63)$ & 834 & $277(33.21)$ & $1.09(0.88,1.35)$ & 836 & $664(79.43)$ & $1.51(1.20,1.92)$ \\
\hline \multicolumn{10}{|l|}{ Age } \\
\hline 19-24 & 128 & $24(18.75)$ & 1.00 (ref) & 127 & $30(23.62)$ & 1.00 (ref) & 127 & $72(56.69)$ & 1.00 (ref) \\
\hline $25-44$ & 676 & $192(28.40)$ & $1.61(0.99,2.62)$ & 675 & $223(33.04)$ & $1.43(0.91,2.25)$ & 676 & 497 (73.52) & $1.80(1.19,2.71)$ \\
\hline $45+$ & 876 & $294(33.56)$ & $2.06(1.27,3.33)$ & 879 & $278(31.63)$ & $1.38(0.88,2.17)$ & 874 & $697(79.75)$ & $2.41(1.60,3.63)$ \\
\hline \multicolumn{10}{|l|}{ Education Level } \\
\hline Low & 317 & $93(29.34)$ & 1.00 (ref) & 319 & $83(26.02)$ & 1.00 (ref) & 320 & 205 (64.06) & 1.00 (ref) \\
\hline Medium & 585 & $151(25.81)$ & $0.80(0.58,1.10)$ & 584 & $157(26.88)$ & $1.03(0.74,1.43)$ & 583 & $424(72.73)$ & $1.15(0.84,1.57)$ \\
\hline High & 705 & $244(34.61)$ & $0.94(0.66,1.34)$ & 704 & $271(38.49)$ & $1.59(1.15,2.20)$ & 704 & $593(84.23)$ & $1.84(1.30,2.59)$ \\
\hline Unknown & 73 & $22(30.14)$ & $0.96(0.54,1.72)$ & 74 & $20(27.03)$ & $0.97(0.54,1.75)$ & 70 & $44(62.86)$ & $1.11(0.63,1.96)$ \\
\hline \multicolumn{10}{|l|}{ Alcohol Use } \\
\hline Low Risk volume & 1234 & $381(30.88)$ & 1.00 (ref) & 1234 & 409 (33.14) & 1.00 (ref) & 1232 & 969 (78.65) & 1.00 (ref) \\
\hline Risky volume & 126 & $34(26.98)$ & $0.82(0.54,1.26)$ & 126 & $27(21.43)$ & $0.55(0.35,0.86)$ & 125 & $95(76.00)$ & $0.97(0.62,1.53)$ \\
\hline High Risk volume & 186 & $53(28.49)$ & $0.94(0.66,1.34)$ & 186 & $58(31.18)$ & $0.97(0.69,1.38)$ & 184 & $124(67.39)$ & $0.74(0.52,1.06)$ \\
\hline Unknown & 134 & $42(31.34)$ & $1.11(0.73,1.69)$ & 135 & $37(27.41)$ & $0.91(0.60,1.40)$ & 136 & $78(57.35)$ & $0.55(0.37,0.82)$ \\
\hline \multicolumn{10}{|l|}{ Site } \\
\hline Comparison & 643 & $162(25.19)$ & 1.00 (ref) & 642 & $197(30.69)$ & 1.00 (ref) & 641 & $451(70.36)$ & 1.00 (ref) \\
\hline Intervention & 1037 & $348(33.56)$ & $1.36(1.08,1.72)$ & 1039 & $334(32.15)$ & $1.02(0.82,1.28)$ & 1036 & $815(78.67)$ & $1.26(0.99,1.60)$ \\
\hline \multicolumn{10}{|l|}{ Wave } \\
\hline 2 & 512 & $140(27.34)$ & 1.00 (ref) & 517 & 155 (29.98) & 1.00 (ref) & 510 & $350(68.63)$ & 1.00 (ref) \\
\hline 3 & 1168 & $370(31.68)$ & $1.07(0.84,1.36)$ & 1164 & $376(32.30)$ & $0.96(0.75,1.21)$ & 1167 & 916 (78.49) & $1.25(0.97,1.60)$ \\
\hline
\end{tabular}

${ }^{1}$ Adjusted for knowledge of alcohol as a carcinogen, sex, age, ethnicity, education level, alcohol use, site, and wave. Note: Bold indicates $p<0.05$. 
Table 3. Adjusted odds ratios (OR) and 95\% confidence intervals (CI) of support for policy by increase in knowledge of alcohol as a carcinogen.

\begin{tabular}{|c|c|c|c|c|c|c|c|c|c|}
\hline \multirow[t]{2}{*}{$\begin{array}{l}\text { Increase in } \\
\text { Knowledge }\end{array}$} & \multicolumn{4}{|c|}{$\begin{array}{l}\text { Availability } \\
\left(N=433^{1}\right)\end{array}$} & \multicolumn{3}{|c|}{$\begin{array}{c}\text { Pricing } \\
\left(\mathrm{N}=431^{1}\right)\end{array}$} & \multicolumn{2}{|r|}{$\begin{array}{l}\text { Marketing } \\
\left(\mathrm{N}=430^{1}\right)\end{array}$} \\
\hline & $\mathbf{N}$ & N (\%) & $\begin{array}{c}\text { Adjusted OR } \\
(95 \% \mathrm{CI})^{2}\end{array}$ & $\mathbf{N}$ & N (\%) & $\begin{array}{c}\text { Adjusted OR } \\
(95 \% \mathrm{CI})^{2}\end{array}$ & $\mathbf{N}$ & N (\%) & $\begin{array}{c}\text { Adjusted OR } \\
(95 \% \text { CI })^{2}\end{array}$ \\
\hline No & 345 & $87(25.22)$ & 1.00 (ref) & 344 & $91(26.45)$ & 1.00 (ref) & 343 & $260(75.80)$ & 1.00 (ref) \\
\hline Yes & 88 & $24(27.27)$ & $1.15(0.66,1.99)$ & 87 & $34(39.08)$ & $1.86(1.11,3.12)$ & 87 & 71 (81.61) & $1.40(0.73,2.71)$ \\
\hline
\end{tabular}

${ }^{1}$ Includes participants that completed both survey waves 1 and 2. ${ }^{2}$ Adjusted for increase in knowledge of alcohol as a carcinogen, sex, age, ethnicity, education level, alcohol use, and site. Note: Bold indicates $p<0.05$. 


\section{Discussion}

Knowledge that alcohol is a risk factor for cancer was associated with greater support for alcohol policies controlling price, marketing, and availability. These findings are in line with previous research examining associations between awareness of the alcohol-cancer link and policy support [35-38]. This study extended previous research by also examining the extent to which policy support is associated with increases in individual-level knowledge that alcohol can cause cancer among a prospective cohort of Canadian drinkers after an alcohol labelling intervention. Participants who became aware that alcohol can cause cancer between waves 1 and 2, before and after a one-month alcohol labelling intervention with a cancer warning label, were almost two times more likely to support alcohol pricing policies relative to individuals with no change in knowledge (i.e., individuals that were not aware that alcohol can cause cancer in wave 2 or that were already aware that alcohol can cause cancer in wave 1). Previous cross-sectional studies in Denmark and England have observed that TV and social media campaigns highlighting the link between alcohol and cancer were associated with higher levels of public awareness and support for alcohol policies [35,38]. Together, these findings suggest that consumer awareness of the health risks of alcohol can be increased and that increasing awareness may have an impact on public support for strengthening alcohol pricing policies, which if implemented, may increase health and wellness within society.

Increasing individual-level knowledge of alcohol as a carcinogen was associated with higher levels of support for alcohol pricing policies in this study, specifically setting a minimum unit price per standard drink of alcohol. Research consistently indicates the positive impact of minimum unit pricing policies for alcohol control, particularly for reducing the sale and consumption of high-strength low-cost products known to cause the most alcohol-related harms [29,69]. A challenge, however, is gaining public support for such an initiative. The current study was conducted among a sample of drinkers (excluded abstainers) in two jurisdictions with the highest per capita alcohol consumption and costs due to alcohol-related harms in Canada [11]. Levels of support for alcohol pricing and availability policies were very low overall, with more participants being opposed to than supporting restrictions on pricing and availability policies. However, increasing individual-level knowledge of alcohol as a carcinogen was associated with higher levels of support for alcohol pricing policies in this study, specifically, setting a minimum unit price per standard drink of alcohol. One potential explanation for the association between increases in knowledge and support for minimum unit pricing policies in this study is that the negative consequences of alcohol are prevalent in the two study site communities [55] and the need for effective interventions at the population-level is urgent. Yet, alcohol pricing policies are relatively weak in these two jurisdictions compared to the rest of Canada. The alcohol pricing structures in Yukon and Northwest Territories do not currently include a set minimum unit price per standard drink of alcohol in off-premise retail outlets [70,71], and high strength alcoholic beverages can be sold at large discounted prices. Finnish and US studies have shown that support for health-related policies varies according to the experiences of survey participants, with higher levels of support for alcohol policies among those who have witnessed alcohol-related disturbances in their communities [72-74]. Alternatively, a Canadian study using aggregated data across the 10 provinces, but excluding the territories, found that higher-consuming jurisdictions are more likely to be biased towards opposing alcohol taxation policies [75]. Other possible explanations for the association between increased knowledge and support for alcohol pricing policy are that support for alcohol pricing policies was low to begin with in this study, particularly compared to support for marketing policies, and it might be easier to increase support levels of policy measures that are lower. Additionally, approximately $60 \%$ of the sample in the current study reported an annual income of at least $\$ 60,000$, and high income populations are less sensitive to price interventions compared to low income populations $[25,69]$. It is not clear why increased knowledge of the alcohol-cancer link did not have a stronger association with support for alcohol availability policies in this study, with the exception that the policy measures used in this study examined support for reduced trading hours and the government-owned off-site retail 
outlets in the two study sites already limit trading hours to six days per week, liquor stores are closed on Sundays.

Largely consistent with previous cross-sectional research, this study found that knowledge of alcohol as a carcinogen was significantly associated with support for policies controlling alcohol availability, pricing and marketing. The magnitude of the associations were also consistent with previously published cross-sectional studies examining population-level effects and the association between increases in individual-level knowledge of the alcohol-cancer link and support for pricing policies observed in this study [36-38]. Other receiver characters associated with support for alcohol pricing, marketing, and availability policies in this study, such as being female, being of older age, having higher levels of education, and consuming lower levels of alcohol, are consistent with previous studies [35,37,76-79]. Moreover, this study also observed, regardless of knowledge of the alcohol-cancer relationship, higher levels of support for alcohol marketing policies, relative to policies controlling the hours alcohol can be sold in off-premise retail outlets and the minimum unit price of alcohol, which are largely consistent with research from the US, Europe, and Australia [35-38,76]. Support towards health behaviour policies that are perceived as less restrictive and target other people and not themselves tends to be higher, specifically policies intended to protect young people [80]. More research is needed to confirm the extent to which efforts to improve awareness that alcohol can cause cancer may reduce the knowledge deficit and positively influence support for these more restrictive policies among the public.

The main strength of our study is the use of prospective research in the context of an alcohol labelling intervention to examine whether increases in individual-level knowledge of alcohol as a carcinogen is associated with policy support. However, our study has limitations. First, this study used only one measure, specifically regarding breast cancer, to test respondents' knowledge of alcohol as a carcinogen. Previous research examining knowledge of alcohol-related cancers report the lowest levels of knowledge for breast cancer compared to other cancers, such as liver and colon $[14,17,81]$. Future research could examine the association between knowledge of alcohol as a risk factor for specific types of cancers and support for alcohol policies. Next, a prompted measure of knowledge of alcohol as a carcinogen was used in this study. There is inconsistency in the literature as to whether prompted or unprompted cancer awareness is a stronger predictor of support for alcohol pricing, marketing, and availability policies [36,38]; thus, both prompted and unprompted cancer awareness measures should be used in future studies to predict support for alcohol policies. Additionally, support for alcohol policies was only measured in survey waves 2 and 3, and not measured in wave 1 in this study. Consequently, participants that only responded in wave 1 were excluded from analyses and prevented analyses examining relationships between changes in both knowledge of alcohol as a carcinogen and policy support. The odds ratios estimating an association between an increase in knowledge and support for alcohol availability and marketing policies did not reach levels of conventional statistical significance. The limited sample size may, at least in part, contribute to not reaching conventional levels of statistical significance, and producing relatively wide confidence intervals and less precise estimates. Lastly, the study cannot provide representative estimates of the population as the response rate was low and the participants were recruited from liquor stores in city centres using systematic recruitment methods. However, given the stores from which the customers were recruited are virtual monopolies for the off-premise sale of alcohol in both experimental sites, they will have been broadly representative of persons purchasing alcohol in those cities. Nevertheless, the sample in this study includes a large percentage of participants who self-reported low levels of alcohol consumption, a population shown to be less defensive to health warning messages relative to higher level consumers [82].

\section{Conclusions}

In the context of a short alcohol labelling intervention, support for alcohol policies affecting alcohol price, availability, and marketing was associated with knowledge that alcohol can cause cancer. Increases in individual-level knowledge that alcohol is a risk factor for cancer was also associated with 
greater support for alcohol pricing policies. Improving knowledge of alcohol consumption health risks, specifically cancer risk, using alcohol warning labels may be an effective strategy for increasing public support for effective alcohol control policies that are currently not well supported, and which, in return, may improve population health.

Author Contributions: Conceptualization, All Authors; Methodology, All Authors.; Software, A.W.; Validation, A.W.; Formal Analysis, A.W.; Investigation, N.S.-M., K.V. and E.H.; Resources, All Authors; Data Curation, A.W., N.S.-M. and E.H.; Writing-original draft preparation, A.W., E.H. and N.S.-M.; Writing-review and editing, All Authors; Visualization, A.W., N.S.-M. and E.H.; Supervision, E.H.; Project administration, N.S.-M.; Funding acquisition, N.S.-M., K.V., T.S., D.H., J.M., T.K.G., C.P. and E.H. All authors have read and agreed to the published version of the manuscript.

Funding: This research was funded by a Health Canada Substance Use and Addictions Program grant, grant \# 1718-HQ-000003. Greenfield's contribution was supported by U.S. National Institute on Alcohol Abuse and Alcoholism grant P50 AA005595.

Acknowledgments: The authors would like to acknowledge all of our Research Assistants that helped with data collections, as well as the liquor control boards, health and social services, and community partners in Yukon and Northwest Territories for their commitment and support in developing and executing this research. Special thanks also go to Mark Petticrew and Melanie Wakefield.

Conflicts of Interest: The authors declare no conflict of interest with the exception of Tim Stockwell, who received research funds and travel expenses from both the Swedish (Systembolaget) and Finnish (ALKO) government retail alcohol monopolies for the conduct of research into the impacts of their policies on alcohol consumption and related harm, T. K. Greenfield whose research has been partially supported by the National Alcohol Beverage Control Association (NABCA), and Catherine Paradis who received funds from Educ'alcool from 2008-2014. The funders had no role in the design of the study; in the collection, analyses, or interpretation of data; in the writing of the manuscript, or in the decision to publish the results.

\section{References}

1. World Health Organization. Global Status Report on Alcohol and Health; WHO Press: Geneva, Switzerland, 2018; Available online: https://www.who.int/substance_abuse/publications/global_alcohol_report/gsr_2018/en/ (accessed on 11 October 2019).

2. International Agency of Research on Cancer. Alcohol Consumption and Ethyl Carbamate. IARC Monogr. Eval. Carcinog. Risks Humans 2010, 96, 1-1379. Available online: https://monographs.iarc.fr/wp-content/ uploads/2018/06/mono96.pdf (accessed on 25 October 2019).

3. International Agency of Research on Cancer. Personal Habits and Indoor Combustions. IARC Monogr. Eval. Carcinog. Risks Humans. 2010, 100E, pp. 1-538. Available online: https://monographs.iarc.fr/wp-content/ uploads/2018/06/mono100E.pdf (accessed on 25 October 2019).

4. Bagnardi, V.; Rota, M.; Botteri, E.; Tramacere, I.; Islami, F.; Fedirko, V.; Scotti, L.; Jenab, M.; Turati, F.; Pasquali, E.; et al. Alcohol consumption and site-specific cancer risk: A comprehensive dose-response meta-analysis. Br. J. Cancer 2015, 112, 580-593. [CrossRef] [PubMed]

5. Global Burden of Disease 2016 Alcohol Collaborators. Alcohol use and burden for 195 countries and territories, 1990-2016: A systematic analysis for the Global Burden of Disease Study 2016. Lancet 2018, 392, 1015-1035. [CrossRef]

6. Choi, Y.J.; Myung, S.K.; Lee, J.H. Light Alcohol Drinking and Risk of Cancer: A Meta-Analysis of Cohort Studies. Cancer. Res. Treat. 2018, 50, 474-487. [CrossRef]

7. Manthey, J.; Shield, K.D.; Rylett, M.; Hasan, O.S.M.; Probst, C.; Rehm, J. Global alcohol exposure between 1990 and 2017 and forecasts until 2030: A modelling study. Lancet 2019, 393, 2493-2502. [CrossRef]

8. Health Canada. Canadian Tobacco, Alcohol and Drugs (CTADS) Survey: 2017 Detailed Tables. 2019. Available online: https://www.canada.ca/en/health-canada/services/canadian-tobacco-alcohol-drugs-survey/ 2017-summary/2017-detailed-tables.html\#t17 (accessed on 25 October 2019).

9. Shield, K.D.; Rylett, M.; Gmel, G.; Gmel, G.; Kehoe-Chan, T.A.; Rehm, J. Global alcohol exposure estimates by country, territory and region for 2005-A contribution to the Comparative Risk Assessment for the 2010 Global Burden of Disease Study. Addiction 2013, 108, 912-922. [CrossRef]

10. Statistics Canada. Table 183-0023: Sales and Per Capita Sales of Alcoholic Beverages by Liquor Authorities and Other Retail Outlets, by Value, Volume, and Absolute Volume. 2017. Available online: www5.statcan.gc. $\mathrm{ca} /$ cansim/a26?lang=eng\&id=1830023 (accessed on 25 October 2019). 
11. Canadian Institute for Health Information. Alcohol Harm in Canada: Examining Hospitalizations Entirely Caused by Alcohol and Strategies to Reduce Alcohol Harm. Available online: https:/www.cihi.ca/sites/ default/files/document/report-alcohol-hospitalizations-en-web.pdf (accessed on 25 October 2019).

12. Canadian Centre on Substance Use and Addiction. Canadian Substance Use Costs and Harms Scientific Working Group. 2018. Available online: https://www.ccsa.ca/sites/default/files/2019-04/CSUCH-CanadianSubstance-Use-Costs-Harms-Report-2018-en.pdf (accessed on 25 October 2019).

13. Canadian Cancer Society. Drinking Habits and Perceived Impact of Alcohol Consumption [Survey Conducted by Leger]; Cancer Care Ontario: Toronto, ON, Canada, 2015.

14. Buykx, P.; Li, J.; Gavens, L.; Lovatt, M.; Gomes de Matos, E.; Holmes, J.; Meier, P. An Investigation of Public Knowledge of the Link between Alcohol and Cancer; University of Sheffield and Cancer Research: Sheffield, UK, 2015; Available online: https://www.cancerresearchuk.org/sites/default/files/an_investigation_of_public_ knowledge_of_the_link_between_alcohol_and_cancer_buykx_et_al.pdf (accessed on 25 October 2019).

15. Cheeta, S.; Halil, A.; Kenny, M.; Sheehan, E.; Zamyadi, R.; Williams, A.L.; Webb, L. Does perception of drug-related harm change with age? A cross-sectional online survey of young and older people. BMJ Open 2018, 8, e021109. [CrossRef]

16. Rehm, J.; Lachenmeier, D.W.; Room, R. Why does society accept a higher risk for alcohol than for other voluntary or involuntary risks? BMC Med. 2014, 12, 189. [CrossRef]

17. The Lancet. Changing the conversation to make drug use safer. Lancet 2018, 391, 1965. [CrossRef]

18. Foster, S.; Gmel, G.; Mohler-Kuo, M. Light and heavy drinking in jurisdictions with different alcohol policy environments. Int. J. Drug Policy 2019, 65, 86-96. [CrossRef]

19. Vineis, P.; Wild, C.P. Global cancer patterns: Causes and prevention. Lancet 2014, 383, 549-557. [CrossRef]

20. Greenfield, T.K.; Cook, W.K.; Karriker-Jaffe, K.J.; Patterson, D.; Kerr, W.C.; Xuan, Z.; Naimi, T.S. The Relationship Between the U.S. State Alcohol Policy Environment and Individuals' Experience of Secondhand Effects: Alcohol Harms Due to Others' Drinking. Alcohol. Clin. Exp. Res. 2019, 43, 1234-1243. [CrossRef] [PubMed]

21. Anderson, P.; Chisholm, D.; Fuhr, D.C. Effectiveness and cost-effectiveness of policies and programmes to reduce the harm caused by alcohol. Lancet 2009, 373, 2234-2246. [CrossRef]

22. Babor, T.; Caetano, R.; Casswell, S.; Edwards, G.; Giesbrecht, N.; Hill, L.; Homel, R.; Osterberg, E.; Rehm, J.; Room, R.; et al. Alcohol: No Ordinary Commodity—Research and Public Policy; Oxford University Press: Oxford, UK, 2003.

23. Burton, R.; Henn, C.; Lavoie, D.; O'Connor, R.; Perkins, C.; Sweeney, K.; Greaves, F.; Ferguson, B.; Beynon, C.; Belloni, A.; et al. A rapid evidence review of the effectiveness and cost-effectiveness of alcohol control policies: An English perspective. Lancet 2017, 389, 1558-1580. [CrossRef]

24. Chisholm, D.; Moro, D.; Bertram, M.; Pretorius, C.; Gmel, G.; Shield, K.; Rehm, J. Are the "Best Buys" for Alcohol Control Still Valid? An Update on the Comparative Cost-Effectiveness of Alcohol Control Strategies at the Global Level. J. Stud. Alcohol Drugs 2018, 79, 514-522. [CrossRef] [PubMed]

25. Holmes, J.; Meng, Y.; Meier, P.S.; Brennan, A.; Angus, C.; Campbell-Burton, A.; Guo, Y.; Hill-McManus, D.; Purshouse, R.C. Effects of minimum unit pricing for alcohol on different income and socioeconomic groups: A modelling study. Lancet 2014, 383, 1655-1664. [CrossRef]

26. Patra, J.; Giesbrecht, N.; Rehm, J.; Bekmuradov, D. Are Alcohol Prices and Taxes an Evidence-Based Approach to Reducing Alcohol-Related Harm and Promoting Public Health and Safety-A Literature Review Conference Report: Beyond the Buzzword: Problematising Drugs. Contemp. Drug Probs. 2012, 39, 7-48. [CrossRef]

27. Room, R.; Schmidt, L.; Rehm, J.; Makela, P. International regulation of alcohol. Br. Med. J. 2008, 337 , a2364. [CrossRef]

28. Wagenaar, A.C.; Salois, M.J.; Komro, K.A. Effects of beverage alcohol price and tax levels on drinking: A meta-analysis of 1003 estimates from 112 studies. Addiction 2009, 104, 179-190. [CrossRef]

29. Stockwell, T.; Auld, M.C.; Zhao, J.; Martin, G. Does minimum pricing reduce alcohol consumption? The experience of a Canadian province. Addiction 2012, 107, 912-920. [CrossRef]

30. Stockwell, T.; Zhao, J.; Martin, G.; Macdonald, S.; Vallance, K.; Treno, A.; Ponicki, W.; Tu, A.; Buxton, J. Minimum alcohol prices and outlet densities in British Columbia, Canada: Estimated impacts on alcohol-attributable hospital admissions. Am. J. Public Health 2013, 103, 2014-2020. [CrossRef] [PubMed] 
31. Moskalewicz, J.; Wieczorek, Ł.; Karlsson, T.; Österberg, E. Social support for alcohol policy: Literature review. Drugs Educ. Prev. Policy 2013, 20, 361-374. [CrossRef]

32. Pechey, R.; Burge, P.; Mentzakis, E.; Suhrcke, M.; Marteau, T.M. Public acceptability of population-level interventions to reduce alcohol consumption: A discrete choice experiment. Soc. Sci. Med. 2014, 113, 104-109. [CrossRef] [PubMed]

33. Hope, A. The ebb and flow of attitudes and policies on alcohol in Ireland 2002-2010. Drug Alcohol Rev. 2014, 33, 235-241. [CrossRef] [PubMed]

34. Pettigrew, S.; Hafekost, C.; Jongenelis, M.; Pierce, H.; Chikritzhs, T.; Stafford, J. Behind Closed Doors: The Priorities of the Alcohol Industry as Communicated in a Trade Magazine. Front. Public Health 2018, 6, 217. [CrossRef]

35. Martin, N.; Buykx, P.; Shevills, C.; Sullivan, C.; Clark, L.; Newbury-Birch, D. Population Level Effects of a Mass Media Alcohol and Breast Cancer Campaign: A Cross-Sectional Pre-Intervention and Post-Intervention Evaluation. Alcohol Alcohol. 2018, 53, 31-38. [CrossRef]

36. Bates, S.; Holmes, J.; Gavens, L.; de Matos, E.G.; Li, J.; Ward, B.; Hooper, L.; Dixon, S.; Buykx, P. Awareness of alcohol as a risk factor for cancer is associated with public support for alcohol policies. BMC Public Health 2018, 18, 688. [CrossRef]

37. Buykx, P.; Gilligan, C.; Ward, B.; Kippen, R.; Chapman, K. Public support for alcohol policies associated with knowledge of cancer risk. Int. J. Drug Policy 2015, 26, 371-379. [CrossRef]

38. Christensen, A.S.P.; Meyer, M.K.H.; Dalum, P.; Krarup, A.F. Can a mass media campaign raise awareness of alcohol as a risk factor for cancer and public support for alcohol related policies? Prev. Med. 2019, 126, 105722. [CrossRef]

39. Wakefield, M.A.; Loken, B.; Hornik, R.C. Use of mass media campaigns to change health behaviour. Lancet 2010, 376, 1261-1271. [CrossRef]

40. World Health Organization. Global Strategy to Reduce the Harmful Use of Alcohol; WHO Press: Geneva, Switzerland, 2010; Available online: https://www.who.int/substance_abuse/msbalcstragegy.pdf (accessed on 11 October 2019).

41. World Health Organization. Alcohol Labelling: A Discussion Document on Policy Options; WHO Regional Office for Europe: Copenhagen, Denmark, 2017; Available online: http://www.euro.who.int/_data/assets/pdf_file/ 0006/343806/WH07_Alcohol_Labelling_full_v3.pdf (accessed on 11 October 2019).

42. Brewer, N.T.; Parada, H.; Hall, M.G.; Boynton, M.H.; Noar, S.M.; Ribisl, K.M. Understanding Why Pictorial Cigarette Pack Warnings Increase Quit Attempts. Ann. Behav. Med. 2019, 53, 232-243. [CrossRef]

43. Greenfield, T. Warning labels: Evidence on harm reduction from long-term American surveys. In Alcohol: Minimizing the Harm; Plant, M., Single, E., Stockwell, T., Eds.; Free Association Books: London, UK, 1997; pp. 105-125.

44. Al-hamdani, M.; Smith, S. Alcohol warning label perceptions: Emerging evidence for alcohol policy. Can. J. Public Health 2015, 106, e395-e400. [CrossRef] [PubMed]

45. Al-Hamdani, M.; Smith, S.M. Alcohol Warning Label Perceptions: Do Warning Sizes and Plain Packaging Matter? J. Stud. Alcohol Drugs 2017, 78, 79-87. [CrossRef] [PubMed]

46. Jongenelis, M.; Pratt, I.S.; Slevin, T.; Pettigrew, S. Effectiveness of Warning Labels at Increasing Awareness of Alcohol-Related Cancer Risk Among Heavy Drinkers. J. Glob. Oncol. 2018, 4. [CrossRef]

47. Pettigrew, S.; Jongenelis, M.I.; Glance, D.; Chikritzhs, T.; Pratt, I.S.; Slevin, T.; Liang, W.; Wakefield, M. The effect of cancer warning statements on alcohol consumption intentions. Health Educ. Res. 2016, 31, 60-69. [CrossRef]

48. Canadian Cancer Statistics Advisory Committee. Canadian Cancer Statistics 2018; Canadian Cancer Society: Toronto, ON, Canada, 2018; Available online: http://www.cancer.ca/ \{\}/media/cancer.ca/CW/cancer\% 20information/cancer\%20101/Canadian\%20cancer\%20statistics/Canadian-Cancer-Statistics-2018-EN.pdf? la=en (accessed on 4 October 2019).

49. Blackwell, A.K.M.; Drax, K.; Attwood, A.S.; Munafo, M.R.; Maynard, O.M. Informing drinkers: Can current UK alcohol labels be improved? Drug Alcohol Depend. 2018, 192, 163-170. [CrossRef]

50. Hammond, D. Health warning messages on tobacco products: A review. Tob. Control 2011, 20, 327-337. [CrossRef] 
51. Hobin, E.; Vallance, K.; Zuo, F.; Stockwell, T.; Rosella, L.; Simniceanu, A.; White, C.; Hammond, D. Testing the Efficacy of Alcohol Labels with Standard Drink Information and National Drinking Guidelines on Consumers' Ability to Estimate Alcohol Consumption. Alcohol Alcohol. 2018, 53, 3-11. [CrossRef]

52. Martin-Moreno, J.M.; Harris, M.E.; Breda, J.; Moller, L.; Alfonso-Sanchez, J.L.; Gorgojo, L. Enhanced labelling on alcoholic drinks: Reviewing the evidence to guide alcohol policy. Eur. J. Public Health 2013, 23, 1082-1087. [CrossRef]

53. Strahan, E.J.; White, K.; Fong, G.T.; Fabrigar, L.R.; Zanna, M.P.; Cameron, R. Enhancing the effectiveness of tobacco package warning labels: A social psychological perspective. Tob. Control 2002, 11, 183-190. [CrossRef]

54. Vallance, K.; Romanovska, I.; Stockwell, T.; Hammond, D.; Rosella, L.; Hobin, E. “We Have a Right to Know": Exploring Consumer Opinions on Content, Design and Acceptability of Enhanced Alcohol Labels. Alcohol Alcohol. 2018, 53, 20-25. [CrossRef] [PubMed]

55. Wettlaufer, A. Can a Label Help me Drink in Moderation? A Review of the Evidence on Standard Drink Labelling. Subst. Use Misuse 2018, 53, 585-595. [CrossRef]

56. Hobin, E.; Weerasinghe, A.; Vallance, K.; Hammond, D.; McGavock, J.; Greenfield, T.; Schoueri-Mychasiw, N.; Paradis, C.; Zhao, J.; Stockwell, T. Testing Alcohol Labels as a Tool to Communicate Cancer Risk to Drinkers: A Real-World Quasi-Experimental Study. J. Stud. Alcohol Drugs. in press.

57. Canadian Partnership Against Cancer. Cancer Control Snapshot 5: Alcohol Use and Cancer in Canada. Available online: http://www.cancerview.ca/idc/groups/public/documents/webcontent/rl_crc_snapshot_5.pdf (accessed on 25 October 2019).

58. Sanderson, S.C.; Waller, J.; Jarvis, M.J.; Humphries, S.E.; Wardle, J. Awareness of lifestyle risk factors for cancer and heart disease among adults in the UK. Patient Educ. Couns. 2009, 74, 221-227. [CrossRef] [PubMed]

59. Vallance, K.; Stockwell, T.; Hammond, D.; Shokar, S.; Schoueri-Mychasiw, N.; Greenfield, T.K.; McGavock, J.; Zhao, J.; Weerasinghe, A.; Hobin, E. Testing the Effectiveness of Enhanced Alcohol Warning Labels and Modifications resulting from alcohol industry interference in Yukon, Canada: Protocol for a Pre-Post Quasi-Experimental Study. J. Med Internet Res.. in press.

60. Austen, I.; Yukon Government Gives in to Liquor Industry on Warning Label Experiment. New York Times. 6 January 2018. Available online: https:/www.nytimes.com/2018/01/06/world/canada/yukon-liquor-alcoholwarnings.html (accessed on 11 October 2019).

61. Statistics Canada. Census Profile, 2016 Census: Northwest Territories [Territory] and Canada [Country]. 2016. Available online: https://www12.statcan.gc.ca/census-recensement/2016/dp-pd/prof/details/page.cfm? Lang $=\mathrm{E} \& \mathrm{Geo} 1=\mathrm{PR} \&$ Code $1=61 \& \mathrm{Geo} 2=\mathrm{PR} \&$ Code2 $=01 \&$ SearchText $=$ northwest $\&$ Search Type $=$ Begins \& SearchPR $=01 \& B 1=A l 1 \& T A B I D=1 \&$ type $=0$ (accessed on 20 November 2019).

62. Statistics Canada. Census Profile, 2016 Census: Yukon [Economic Region], Yukon and Yukon [Territory]. 2016. Available online: https://www12.statcan.gc.ca/census-recensement/2016/dp-pd/prof/details/page. cfm?Lang=E\&Geo1=ER\&Code1=6010\&Geo2=PR\&Code2=60\&SearchText=Yukon\&SearchType=Begins\& SearchPR=01\&B1 =All\&GeoLevel=PR\&GeoCode=6010\&TABID=1\&type=0 (accessed on 20 November 2019).

63. What We Heard. Yukon Liquor Act Progress Report. Available online: https://yukon.ca/sites/yukon.ca/files/ ylc-what-we-heard-liquor-act.pdf (accessed on 25 October 2019).

64. Weiss, B.D.; Mays, M.Z.; Martz, W.; Castro, K.M.; DeWalt, D.A.; Pignone, M.P.; Mockbee, J.; Hale, F.A. Quick assessment of literacy in primary care: The newest vital sign. Ann. Fam. Med. 2005, 3, 514-522. [CrossRef] [PubMed]

65. Heeb, J.L.; Gmel, G. Measuring alcohol consumption: A comparison of graduated frequency, quantity frequency, and weekly recall diary methods in a general population survey. Addict. Behav. 2005, 30, 403-413. [CrossRef] [PubMed]

66. Butt, P.; Beirness, D.; Cesa, F.; Gliksman, L.; Paradis, C.; Stockwell, T. Alcohol and Health in Canada: A Summary of Evidence and Guidelines for Low-Risk Drinking; Canadian Centre on Substance Abuse: Ottawa, ON, Canada, 2011.

67. Rehm, J.; Greenfield, T.K.; Walsh, G.; Xie, X.; Robson, L.; Single, E. Assessment methods for alcohol consumption, prevalence of high risk drinking and harm: A sensitivity analysis. Int. J. Epidemiol. 1999, 28, 219-224. [CrossRef] 
68. American Association for Public Opinion Research. Standard Definitions: Final Dispositions of Case Codes and Outcome Rates for Surveys, 7th ed.; The American Association for Public Opinion Research: Lenexa, KS, USA, 2011; Available online: https://www.esomar.org/uploads/public/knowledge-and-standards/codes-andguidelines/ESOMAR_Standard-Definitions-Final-Dispositions-of-Case-Codes-and-Outcome-Rates-forSurveys.pdf (accessed on 25 October 2019).

69. Meier, P.S.; Holmes, J.; Angus, C.; Ally, A.K.; Meng, Y.; Brennan, A. Estimated Effects of Different Alcohol Taxation and Price Policies on Health Inequalities: A Mathematical Modelling Study. PLoS Med. 2016, 13, e1001963. [CrossRef]

70. Chow, C.; Vallance, K.; Wettlaufer, A.; Stockwell, T.; Giesbrecht, N.; April, N.; Asbridge, M.; Callaghan, R.; Cukier, S.; Davis-MacNevin, P.; et al. Reducing Alcohol-Related Harms and Costs in Northwest Territories: A Policy Review; Canadian Institute for Substance Use Research, University of Victoria: Victoria, BC, Canada, 2019.

71. Chow, C.; Vallance, K.; Wettlaufer, A.; Stockwell, T.; Giesbrecht, N.; April, N.; Asbridge, M.; Callaghan, R.; Cukier, S.; Davis-MacNevin, P.; et al. Reducing Alcohol-Related Harms and Costs in Yukon: A Policy Review; Canadian Institute for Substance Use Research, University of Victoria: Victoria, BC, Canada, 2019.

72. Holmila, M.; Mustonen, H.; Österberg, E.; Raitasalo, K. Public opinion and community-based prevention of alcohol-related harms. Addict. Res. Theory 2009, 17, 360-371. [CrossRef]

73. Osterberg, E.; Lindeman, M.; Karlsson, T. Changes in alcohol policies and public opinions in Finland 2003-2013. Drug Alcohol Rev. 2014, 33, 242-248. [CrossRef] [PubMed]

74. Greenfield, T.K.; Karriker-Jaffe, K.J.; Giesbrecht, N.; Kerr, W.C.; Ye, Y.; Bond, J. Second-hand drinking may increase support for alcohol policies: New results from the 2010 National Alcohol Survey. Drug Alcohol Rev. 2014, 33, 259-267. [CrossRef] [PubMed]

75. Macdonald, S.; Stockwell, T.; Luo, J. The relationship between alcohol problems, perceived risks and attitudes toward alcohol policy in Canada. Drug Alcohol Rev. 2011, 30, 652-658. [CrossRef]

76. Greenfield, T.K.; Ye, Y.; Giesbrecht, N. Alcohol Policy Opinions in the United States over a 15-Year Period of Dynamic per Capita Consumption Changes: Implications for Today's Public Health Practice. Contemp. Drug Probl. 2007, 34, 649-680. [CrossRef]

77. Li, J.; Lovatt, M.; Eadie, D.; Dobbie, F.; Meier, P.; Holmes, J.; Hastings, G.; MacKintosh, A.M. Public attitudes towards alcohol control policies in Scotland and England: Results from a mixed-methods study. Soc. Sci. Med. 2017, 177, 177-189. [CrossRef] [PubMed]

78. Wilkinson, C.; Room, R.; Livingston, M. Mapping Australian public opinion on alcohol policies in the new millennium. Drug Alcohol Rev. 2009, 28, 263-274. [CrossRef] [PubMed]

79. Banerjee, J.; Squires, J.; Parkinson, T. Public Perceptions of Alcohol Pricing; Home Office: London, UK, 2010.

80. Diepeveen, S.; Ling, T.; Suhrcke, M.; Roland, M.; Marteau, T.M. Public acceptability of government intervention to change health-related behaviours: A systematic review and narrative synthesis. BMC Public Health 2013, 13, 756. [CrossRef]

81. Scheideler, J.K.; Klein, W.M.P. Awareness of the Link between Alcohol Consumption and Cancer across the World: A Review. Cancer Epidemiol. Biomark. Prev. 2018, 27, 429-437. [CrossRef]

82. Brown, S.; Locker, E. Defensive responses to an emotive anti-alcohol message. Psychol. Health 2009, 24, 517-528. [CrossRef]

(C) 2020 by the authors. Licensee MDPI, Basel, Switzerland. This article is an open access article distributed under the terms and conditions of the Creative Commons Attribution (CC BY) license (http://creativecommons.org/licenses/by/4.0/). 